\title{
Survival and prognostic factors in conventional central chondrosarcoma
}

\author{
Julian Fromm, Alexander Klein ${ }^{1}$, Andrea Baur-Melnyk², Thomas Knösel ${ }^{3}$, Lars Lindner ${ }^{4}$, Christof Birkenmaier $^{1}$, \\ Falk Roeder ${ }^{5,6}$, Volkmar Jansson ${ }^{1}$ and Hans Roland Dürr ${ }^{*}$
}

\begin{abstract}
Background: Chondrosarcoma is the second most frequent primary malignant bone tumor. Treatment is mainly based on surgery. In general, wide resection is advocated at least in G2 and G3 tumors. But which margins should be achieved? Does localization as for example in the pelvis have a higher impact on survival than surgical margins themselves?

Methods: From 1982 to 2014, 87 consecutive patients were treated by resection. The margin was defined as R0 (wide resection), R1 (marginal resection) or, R2 if the tumor was left intentionally. All patients were followed for evidence of local recurrence or distant metastasis. Overall and recurrence-free survival were calculated, significance analysis was performed.

Results: In 54 (62\%) cases a R0 resection, in 31 (36\%) a R1 and in 2 (2\%) patients a R2-resection was achieved. Histology proved to be G1 in 37 patients (43\%), G2 in 41 (47\%) and G3 in 9 cases (10\%). 5-year local recurrence-free survival (LRFS) was 75\%. Local recurrence-free survival showed a significant association with the margin status and the localization of the tumor with pelvic lesions doing worst. Metastatic disease was initially seen in 4 patients (4. 6\%), 19 others developed metastatic disease during follow-up. Overall survival of the entire group at 5 and 10 years were 79 and $75 \%$, respectively. The quality of surgical margins and the presence of local recurrence did not influence overall survival in a multivariate analysis. Pelvic lesions had a worse prognosis as did higher grades of the tumor, metastatic disease and age.

Conclusions: The mainstay of therapy in Chondrosarcoma remains surgery. Risk factors as grading, metastatic disease, age and location significantly influence overall survival. Margin status (RO vs. R1) did influence local recurrence-free survival but not overall survival. Chondrosarcomas of the pelvis have a higher risk of local recurrence and should be treated more aggressively.
\end{abstract}

Keywords: Chondrosarcoma, Surgery, Margin status, Recurrence, Prognostic factors

\section{Background}

Following Osteosarcoma, chondrosarcoma (CS) is the second most frequent primary malignant bone tumor accounting for approximately $20 \%$ of all bone sarcomas [1]. It constitutes a heterogeneous group of tumors characterized by the production of cartilaginous matrix [2]. Central (conventional) CS represents about $75 \%$ of the group. With the introduction of the current WHO classification

\footnotetext{
* Correspondence: hans_roland.duerr@med.uni-muenchen.de

${ }^{1}$ Musculoskeletal Oncology, Department of Orthopedics, Physical Medicine and Rehabilitation, University Hospital, Ludwig-Maximilians-University, Campus Grosshadern, Marchioninistr. 15, D-81377 Munich, Germany Full list of author information is available at the end of the article
}

in 2013 Chondrosarcoma grade I (now officially termed atypical cartilaginous tumor) was reclassified as an intermediate (locally aggressive) tumor, better reflecting its clinical behavior [2]. In these difficult cases, the differential diagnosis towards benign enchondromas is based on a combination of pathology, radiology and clinical features and hence requires a close multidisciplinary assessment [3].

Treatment is mainly based on surgery and chemotherapy is less effective because of a low mitotic index and poor vascularity $[4,5]$. Radiotherapy is effective but requires substantial dosage [6].

(c) The Author(s). 2018 Open Access This article is distributed under the terms of the Creative Commons Attribution 4.0 International License (http://creativecommons.org/licenses/by/4.0/), which permits unrestricted use, distribution, and reproduction in any medium, provided you give appropriate credit to the original author(s) and the source, provide a link to the Creative Commons license, and indicate if changes were made. The Creative Commons Public Domain Dedication waiver (http://creativecommons.org/publicdomain/zero/1.0/) applies to the data made available in this article, unless otherwise stated. 
In general, wide resection is advocated at least in G2 and G3 tumors. It is assumed that patients with CS have an excellent prognosis after adequate surgery [4] but reviewing the literature and our own results, such assumptions should be looked at in a more detailed fashion. Even the G1 lesions have a risk of metastasis of 6\% [7]. There is no clear consensus on what exactly constitutes "adequate surgery". Which margins should be achieved? Does localization as for example in the pelvis have a higher impact on survival than surgical margins taken for themselves? In a metaanalysis on 1114 patients published in 2015, the surgical margin were not identified as an independent predictor of overall survival [8]. In consequence, the traditional dogma of adequate margins, as stated by some authors $[9,10]$ had to be called into question.

The main aim of this retrospective study was to analyze a homogenous group of patients with primary central CS of bone, treated at a single tumor center. We sought to determine prognostic factors for overall and local recurrence-free survival. Secondary aim was to asses our own results on the background of the published data.

\section{Methods}

From 1982 to 2014, 87 consecutive patients with chondrosarcoma of the extremities, pelvis and trunk wall were treated at our institution. All tumors had a diagnosis of chondrosarcoma based on histological features and immunohistochemistry.

Prior to surgical resection, predominantly magnetic resonance imaging (MRI) and in some cases computed tomography (CT) was used to define size and localization of the tumor. A CT scan of the chest was performed to determine the presence or absence of metastatic disease.

All patients underwent surgical resection. The margin was defined as R0 if a rim of healthy tissue around the lesion was present (wide resection) or R1 if the margins were contaminated but the tumor capsule remained closed (marginal resection). In select patients, a planned partial resection was performed in order to avoid severely mutilating surgery. This was classified as a R2 resection.

\section{Statistical analysis}

All patients were followed for evidence of local recurrence (LR) or distant metastasis in general by regional MRI scans and chest radiographs. Clinical outcomes of local recurrence (LR), local recurrence-free survival (LRFS) and overall survival (OS) were used for assessment. LRFS and OS were defined either as the time from surgery to the first occurrence of local recurrence or to death from any cause. For statistical analysis, overall and local recurrence-free survival were calculated according to the Kaplan-Meier method. Significance analysis was performed using the Log-Rank, the Chi-Square test or the Cox proportional-hazards regression model. A $P$ value of less than 0.05 was considered statistically significant. The data analysis software used was MedCalc ${ }^{\circ}$ (MedCalc Software, Ostend, Belgium).

\section{Results}

The median age of the 54 male and 33 female patients was 51.7 years (mean 50.3, range 15-83). The lower extremity was involved in 44 cases (29 femur, 18 of them proximal; 11 tibia, 10 of them proximal; fibula and feet 2 each), the upper extremity in 10 (7 humerus, 5 of them proximal; radius, ulna and hand 1 each), the pelvis in 21 and the trunk in 12 (8 scapula, 2 ribs, clavicle and thoracic spine 1 each) patients. Fifty patients (57.5\%) showed extraosseous tumor growth.

The median duration of symptoms prior to diagnosis was 9 months (range, 0-358) and the majority of patients $(44=52 \%)$ complained of pain, $11(13 \%)$ of swelling. A pathologic fracture led to the diagnosis in $6(7 \%)$ patients. Neurological impairment or restriction of movement was seen occasionally. 70 (81\%) patients had a biopsy or histology before surgery. In 2 cases, the biopsy was interpreted as a cartilaginous exostosis and in 3 cases as an enchondroma. Four patients had already undergone surgery at other institutions by means of intramedullary nailing or by resection and endoprosthetic reconstruction. In these cases, the tumor had either gone unidentified or it had been underestimated. Only 4 patients had metastatic disease initially.

Resections of the tumor alone were performed in 42 cases (48\%), resections and reconstructions with megaendoprostheses in 24 cases (28\%), amputations in 11 patients (13\%) and curettages in 10 instances (11\%). A wide (R0) resection was performed in $54(62 \%)$ cases, a marginal (R1) resection in 31 cases (36\%) and an R2-resection in 2 (2\%) patients. With pelvic lesions, 48\% of surgical margins were either R1 or R2, at the lower extremity $41 \%$, at the upper extremity $20 \%$ and at the trunk $25 \%$ (n.s.). Histology proved to be G1 in 37 patients (43\%), G2 in 41 (47\%) and G3 in 9 cases (10\%).

In 20 patients $(23 \%)$, surgical revisions due to complications had to be performed. This included:

Nine revisions due to dislocation or loosening of implants or bone grafts, 6 deep infections, 2 hematomas, and more aggressive tumor resection, neurological impairment and vessel injury in 1 case each.

In 63 surviving patients, the median follow-up time from surgery to last information on the patient was 68 months (range, 0-379). One patient was lost to follow-up less than 12 months after surgery, 8 patients had a follow-up of 12-24 months. Twenty-four patients deceased during follow-up. 


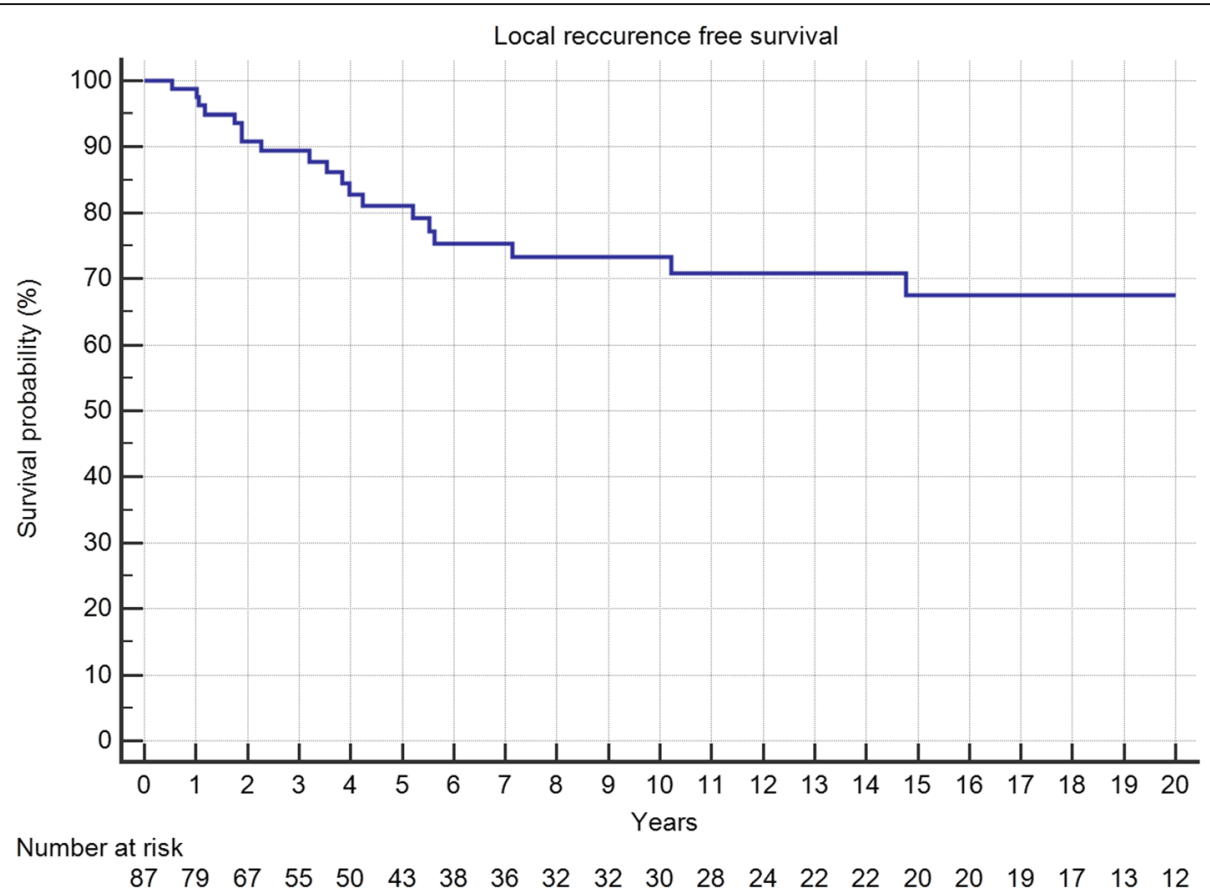

Fig. 1 Local recurrence-free survival in 87 patients with central chondrosarcoma

Five-year local recurrence-free survival was $75 \%$. In total, 21 (24\%) patients developed local recurrences, of which $52 \%$ occured in the first 12 months and $81 \%$ in the first 24 months after surgery (Fig. 1). The latest LR was seen after 10 years. Local recurrence-free survival showed a significant association with the margin status and the localization of the tumor with pelvic lesions doing worst (Table 1, Figs. 2 and 3). In multivariate analysis, both kept significance.

Metastatic disease was initially seen in 4 patients (4.6\%). One of those patients stayed free of disease after resection, 19 others developed metastatic disease during follow-up. At final follow-up, 22 (23\%) patients had metastatic disease, 13 of which were located in the lung, 3 in the spine, one in the femur, one in visceral organs and 4 in multiple localizations. Only 5 of these patients were alive with disease at final follow-up. Of these 22 patients with metastatic disease, only 8 also had a LR (36\%) whereas $20 \%$ of non-metastasized patients had LR which was not statistically significant. Grading showed a trend towards metastatic disease in follow-up with $14 \%$ in G1, 30\% in G2 and 44\% in G3 tumors but without statistical significance $(p=0.0815)$.

Overall survival of the entire group at 5 and 10 years was 79 and $75 \%$, respectively. Grading proved to be a significant factor (Fig. 4, $p=0.0099$ ) as was metastatic disease (Fig. 5, $p<0.0001$ ). Local recurrence also had a strong effect (Fig. 6a, $p=0.0219$ ). Regarding margin status (Fig. 6b, n.s.) and localization (Fig. 7) only the latter had an influence on survival $(p=0.0008)$.

Table 1 Factors influencing local recurrence (margin status, location) and local recurrence free survival

\begin{tabular}{|c|c|c|c|c|c|c|}
\hline Local recurrence & No & Yes & $p$-value & 5-year LRFS & 10-year LRFS & $p$-value \\
\hline$\overline{\mathrm{RO}}$ & 45 (83\%) & $9(17 \%)$ & $0.1025^{*}$ & $84.7 \%$ & $81.4 \%$ & $0.0204^{+}$ \\
\hline R1 & $20(65 \%)$ & $11(35 \%)$ & & $61.9 \%$ & $61.9 \%$ & \\
\hline R2 & $1(50 \%)$ & $1(50 \%)$ & & $0 \%$ & $0 \%$ & \\
\hline Upper Extremity & $10(100 \%)$ & $0(0 \%)$ & $0.0568^{*}$ & $100 \%$ & $100 \%$ & $0.053^{+}$ \\
\hline Lower Exremity & 35 (80\%) & $9(20 \%)$ & & $79.0 \%$ & $79.0 \%$ & \\
\hline Pelvis & $12(57 \%)$ & $9(43 \%)$ & & $55.7 \%$ & $44.7 \%$ & \\
\hline Trunk & $9(75 \%)$ & $3(25 \%)$ & & $75.0 \%$ & $75.0 \%$ & \\
\hline
\end{tabular}

"Chi-squared test;

+'Logrank test 


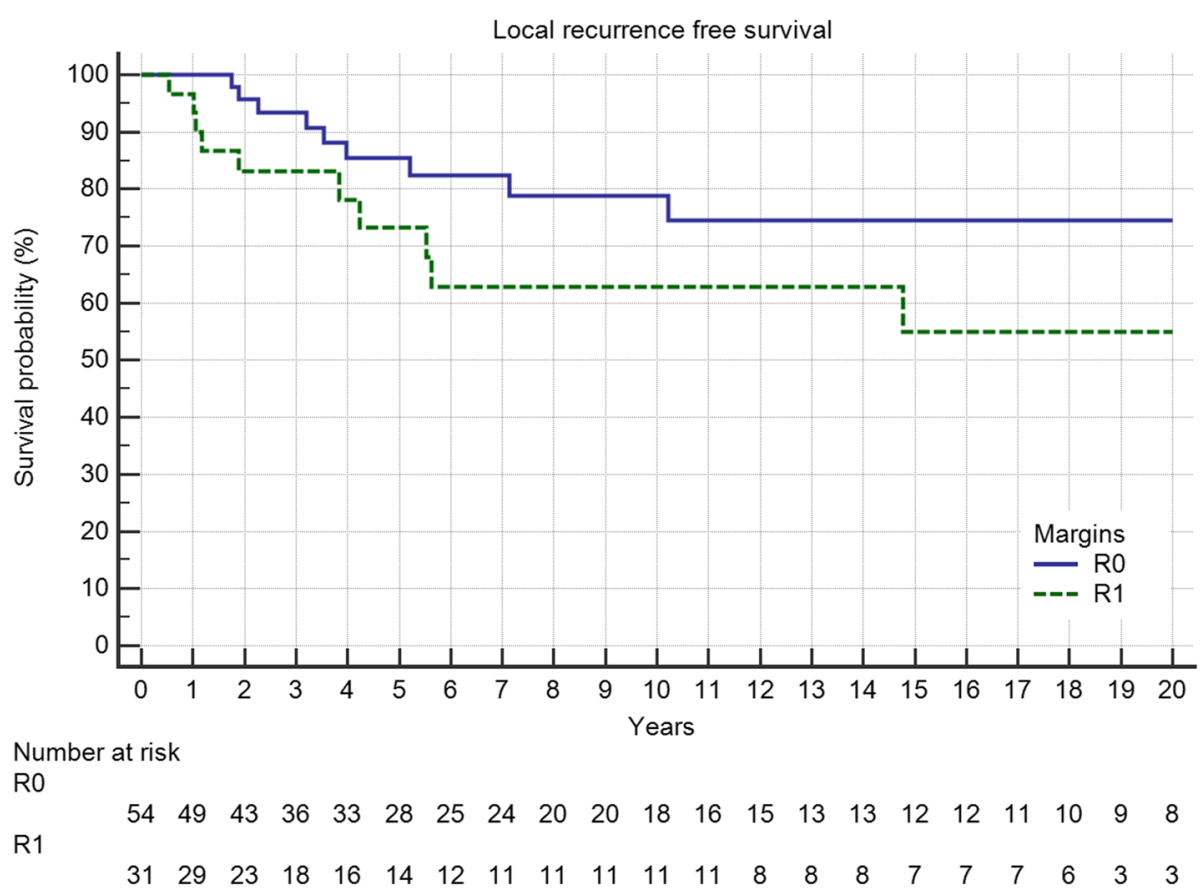

Fig. 2 The impact of surgical margins on local recurrence-free survival in R0 and R1 resected patients $(p=0.05)$

In general, male and female patients showed no difference whereas age with a cut-off of 50 years was a significant predictor of outcome (Fig. 8, $p=0.019$ ).

As shown in Table 2, the quality of surgical margins and the presence of local recurrence did not influence overall survival in a multivariate analysis. Pelvic lesions led to a worse prognosis as did higher tumor grade, presence of metastatic disease and greater age.

\section{Discussion}

Age in general is a very strong factor of overall survival as shown in data out of the SEER Database (USA) [11].

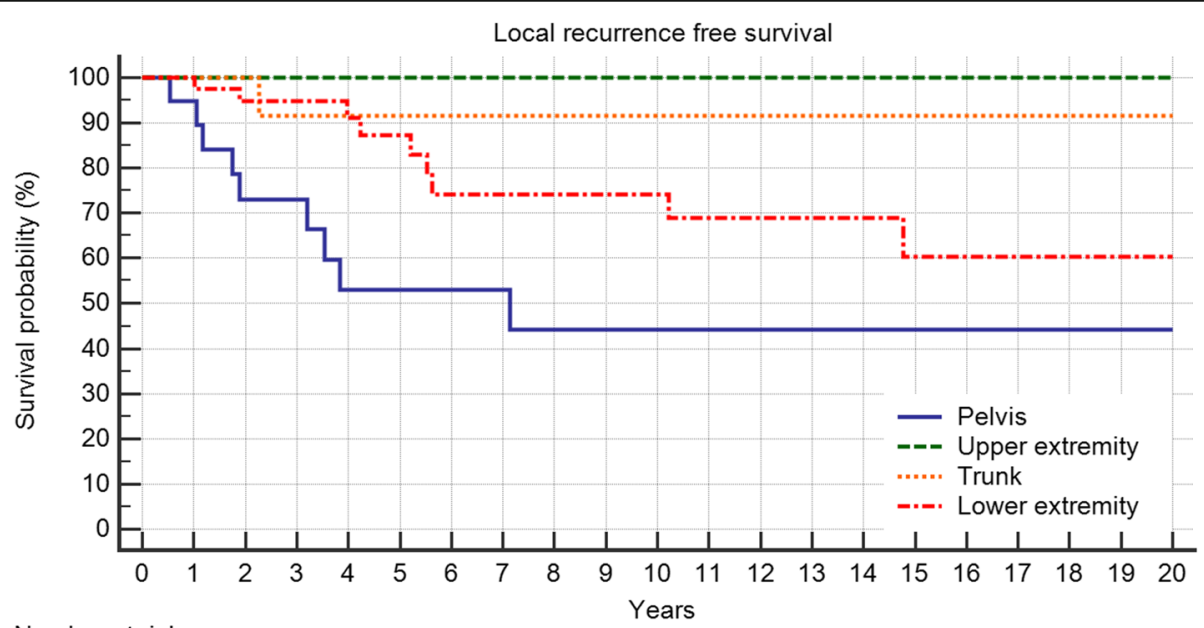

Number at risk

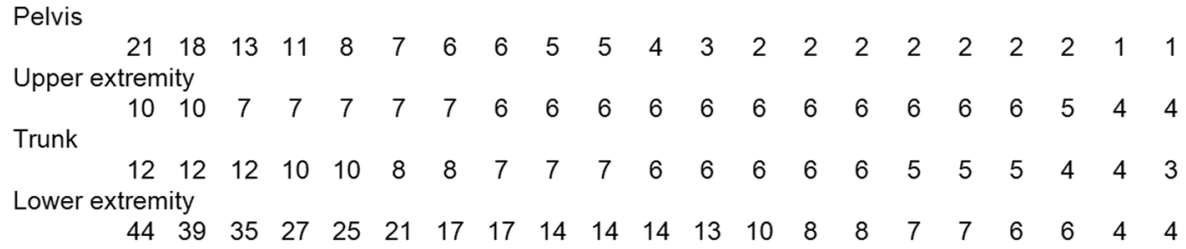

Fig. 3 The impact of tumor localization on local recurrence-free survival $(p=0.0532)$ 


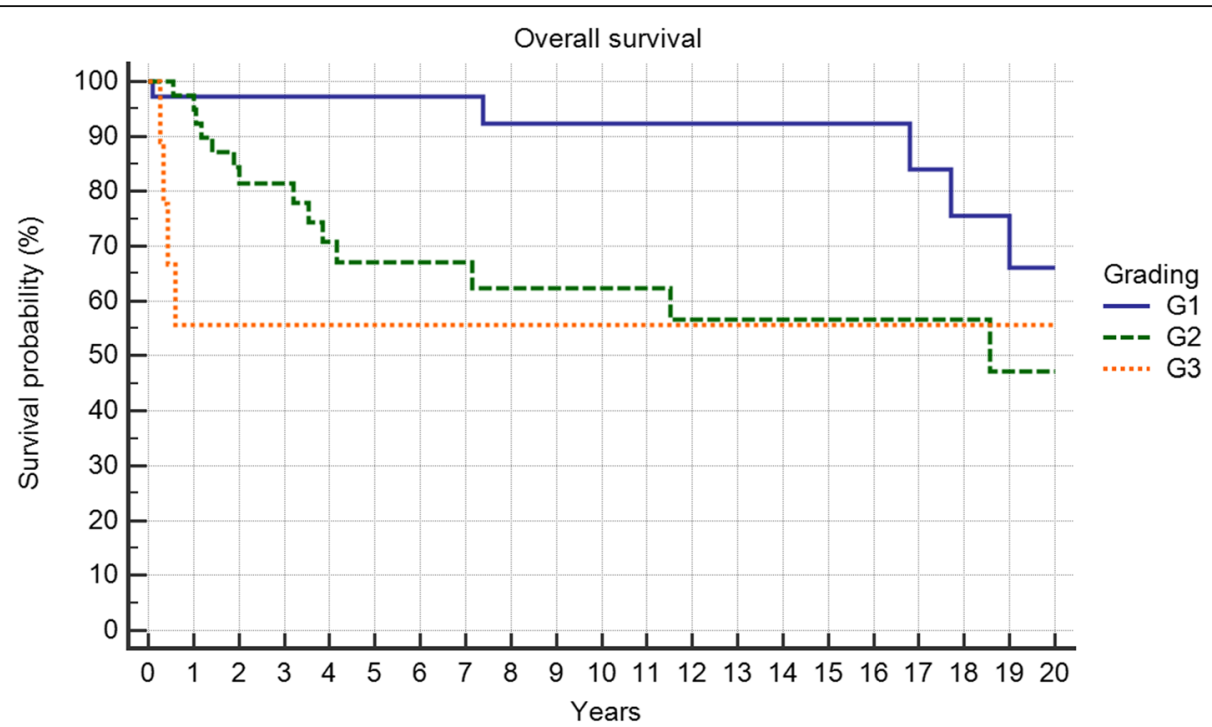

Number at risk

G1

G2

$\begin{array}{lllllllllllllllllllll}37 & 35 & 34 & 29 & 28 & 24 & 21 & 20 & 19 & 19 & 18 & 16 & 14 & 13 & 13 & 11 & 11 & 10 & 9 & 7 & 6\end{array}$

G3

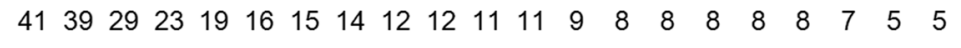

$\begin{array}{lllllllllllllllllllll}9 & 5 & 4 & 3 & 3 & 3 & 2 & 2 & 1 & 1 & 1 & 1 & 1 & 1 & 1 & 1 & 1 & 1 & 1 & 1 & 1\end{array}$

Fig. 4 Overall survival is strongly influenced by tumor grading $(p=0.0099)$

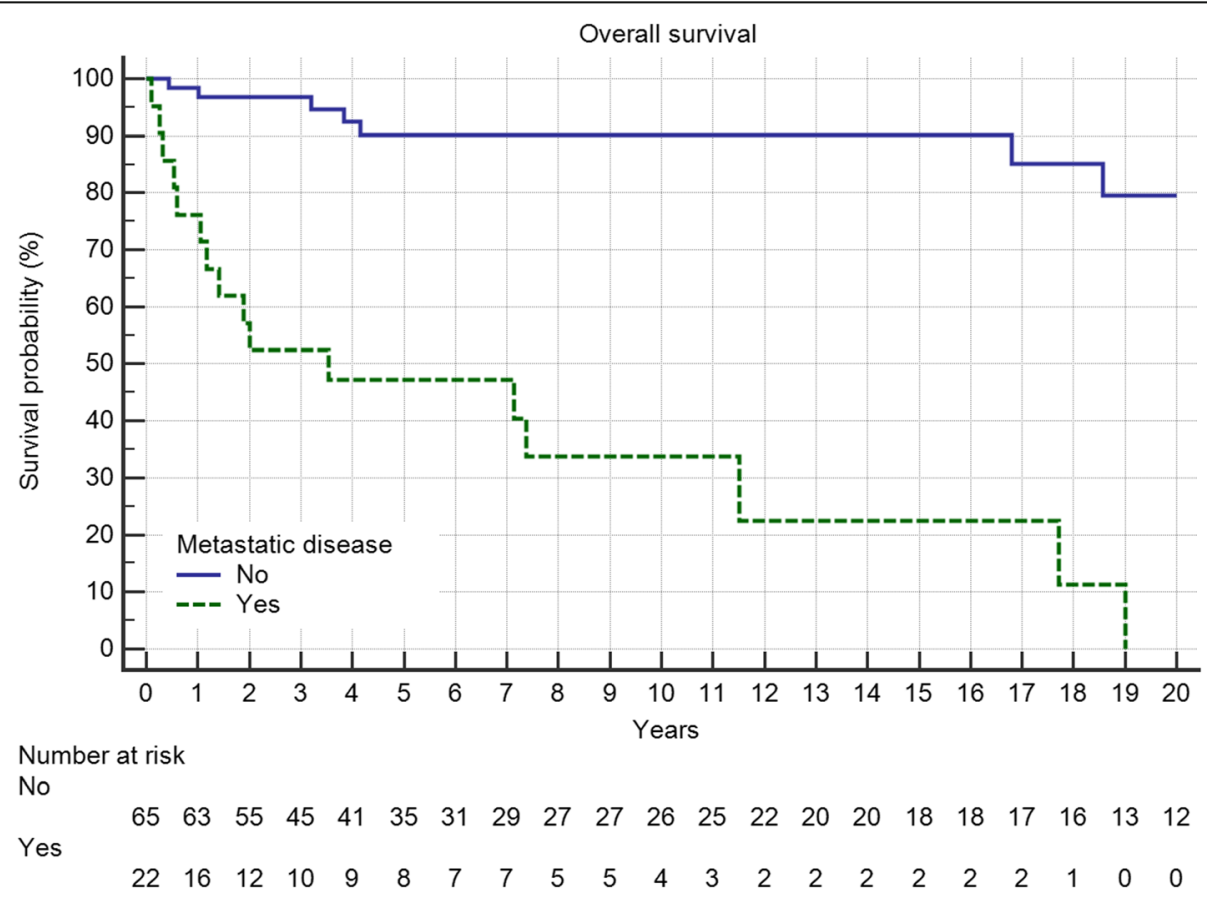

Fig. 5 Metastatic disease in 22 patients significantly deteriorates overall survival $(p<0.0001)$ 

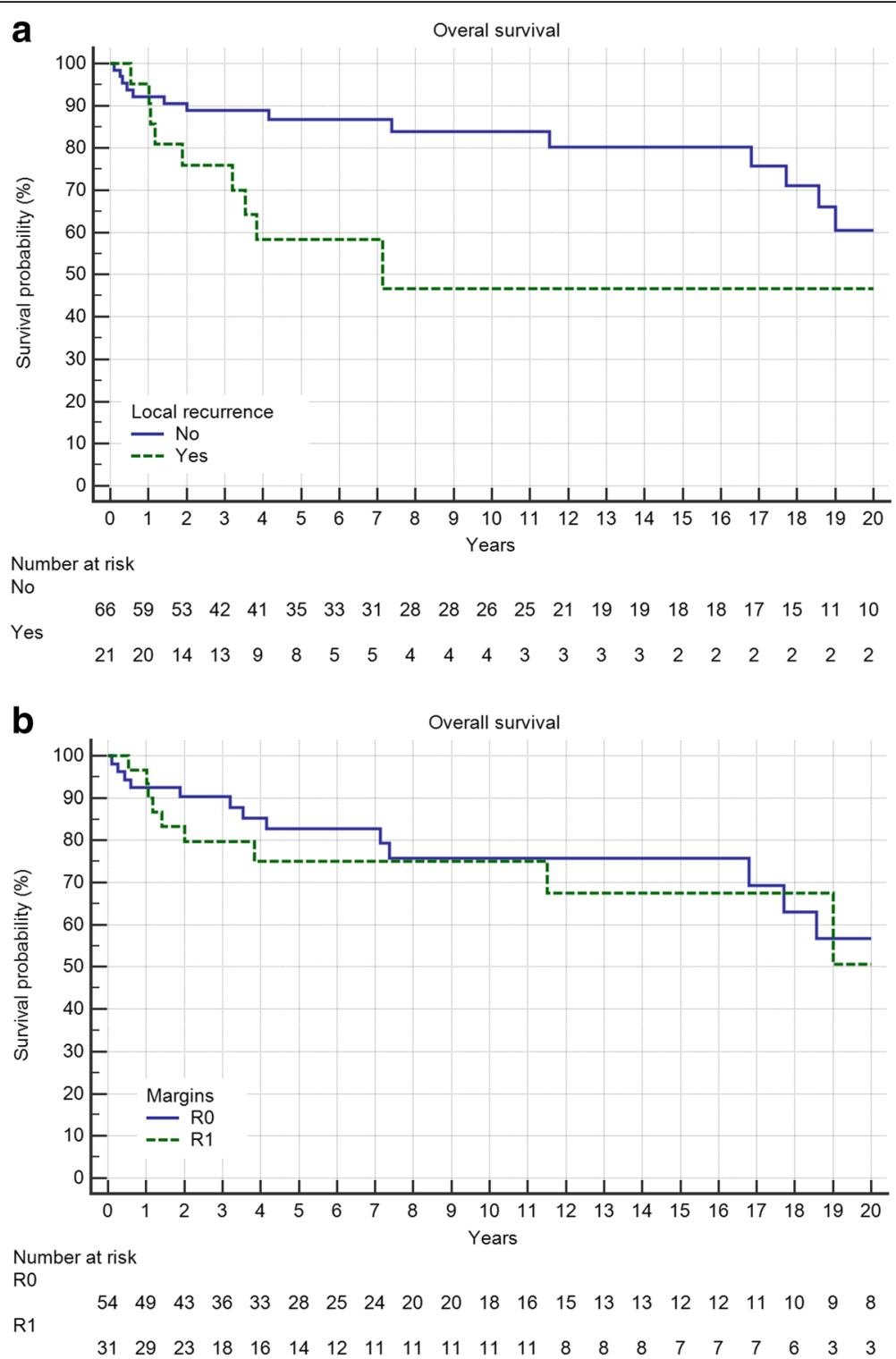

Fig. 6 a Local recurrence in 21 patients reduces overall survival $(p=0.0219)$. $\mathbf{b}$ The surgical margin (R2 only 2 cases) does not influence overall survival (n.s)

Location is undoubtedly also an important aspect. As highly significantly shown in our data, pelvic location of a chondrosarcoma has a worse prognosis. This kept significance also in multivariate analysis. Our 5 and 10-year survival rates in those patients are 50 and $42 \%$, respectively. In central chondrosarcomas, published 10-year survival rates vary between 54 and $88 \%$ [12-17]. This variability in survival depends very much on whether peripheral chondrosarcomas were included and how many patients in the study group had a low-grade chondrosarcoma or recurrent disease. Regarding margins, in pelvic lesions these were associated with $\operatorname{LR}[12,13,16$, 17] but not OS $[12,15,17]$. In other studies LR did clearly influence OS [12-14]. However, the opposite observation, indications that LR did not influence OS has also been published [16]. Some authors showed that LR influenced metastatic disease and hence secondarily OS [13].

The main conclusion in summarizing the published literature and our own data is, that chondrosarcoma of the pelvis does exhibit a more aggressive behaviour and should not be curetted even in low-grade tumors. Local recurrence might lead to dedifferentiation and metastatic disease.

In general, low-grade central CS showed a good prognosis with a 5- and 10-year OS of 97 and $92 \%$. But 5 of our 


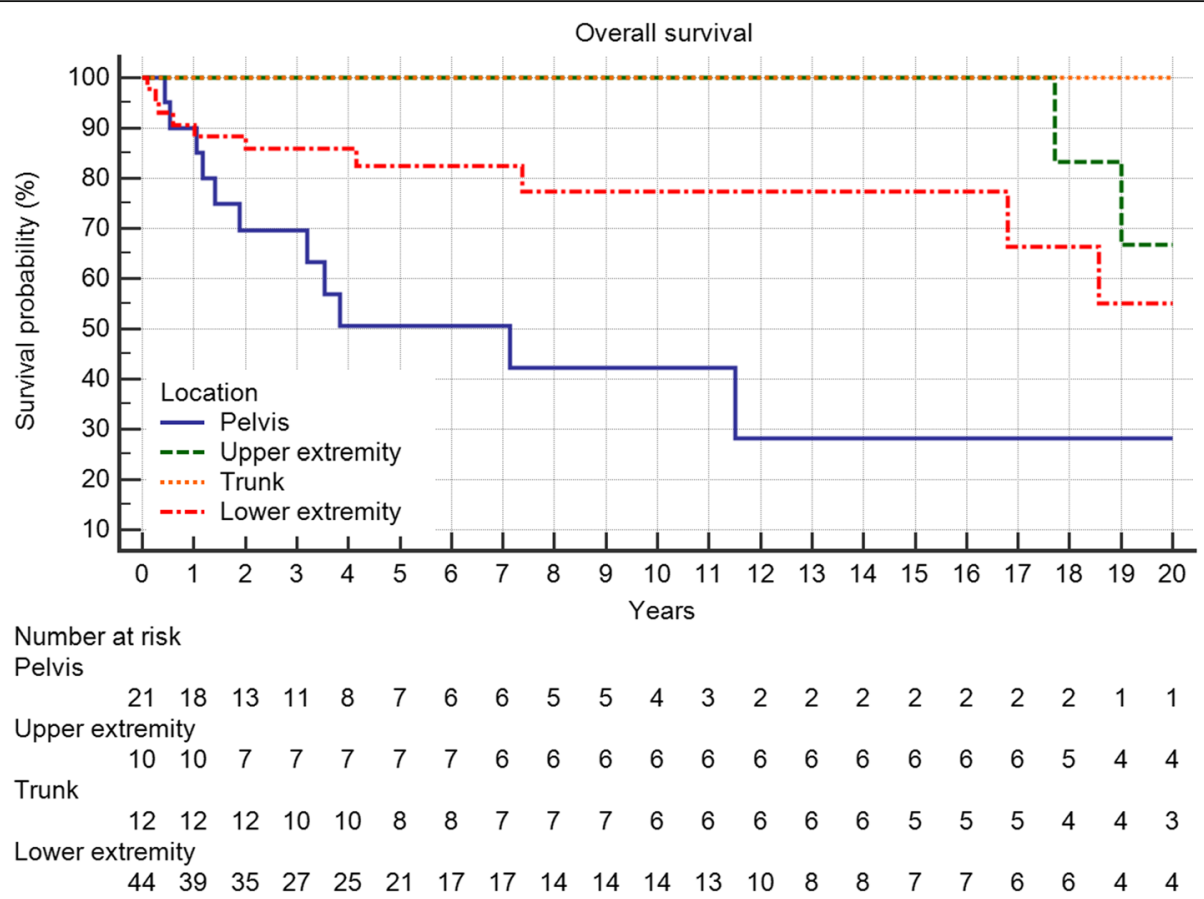

Fig. 7 A pelvic location is worse in respect to overall survival $(p=0.0008)$

37 patients (14\%) developed LR and 6 (16\%) developed metastatic disease (MD), 4 of which eventually (11\%) died from it. The published data on G1 chondrosarcoma is conflicting. From 0\% LR and MD [18, 19], 2\% LR and 0\% MD [20], 3\% LR and 3\% MD [21], 4\% LR and 0\% MD [22], 5\% LR and 0\% MD [23], 6\% LR and 0\% MD [24, 25],
9\% LR and 0\% MD [26], 11\% LR and 3\% MD [27], 13\% LR and $4 \% \mathrm{MD}$ [28], 13\% LR and 5\% MD [29] to 18\% LR and $6 \% \mathrm{MD}$ [7] a variety of different results are reported. 5 -year survival ranges from 82 to $99 \%$ and 10 -year survival from 89 to $95 \%$ [8]. This reflects the problem of differentiation of benign enchondromas and atypical cartilaginous

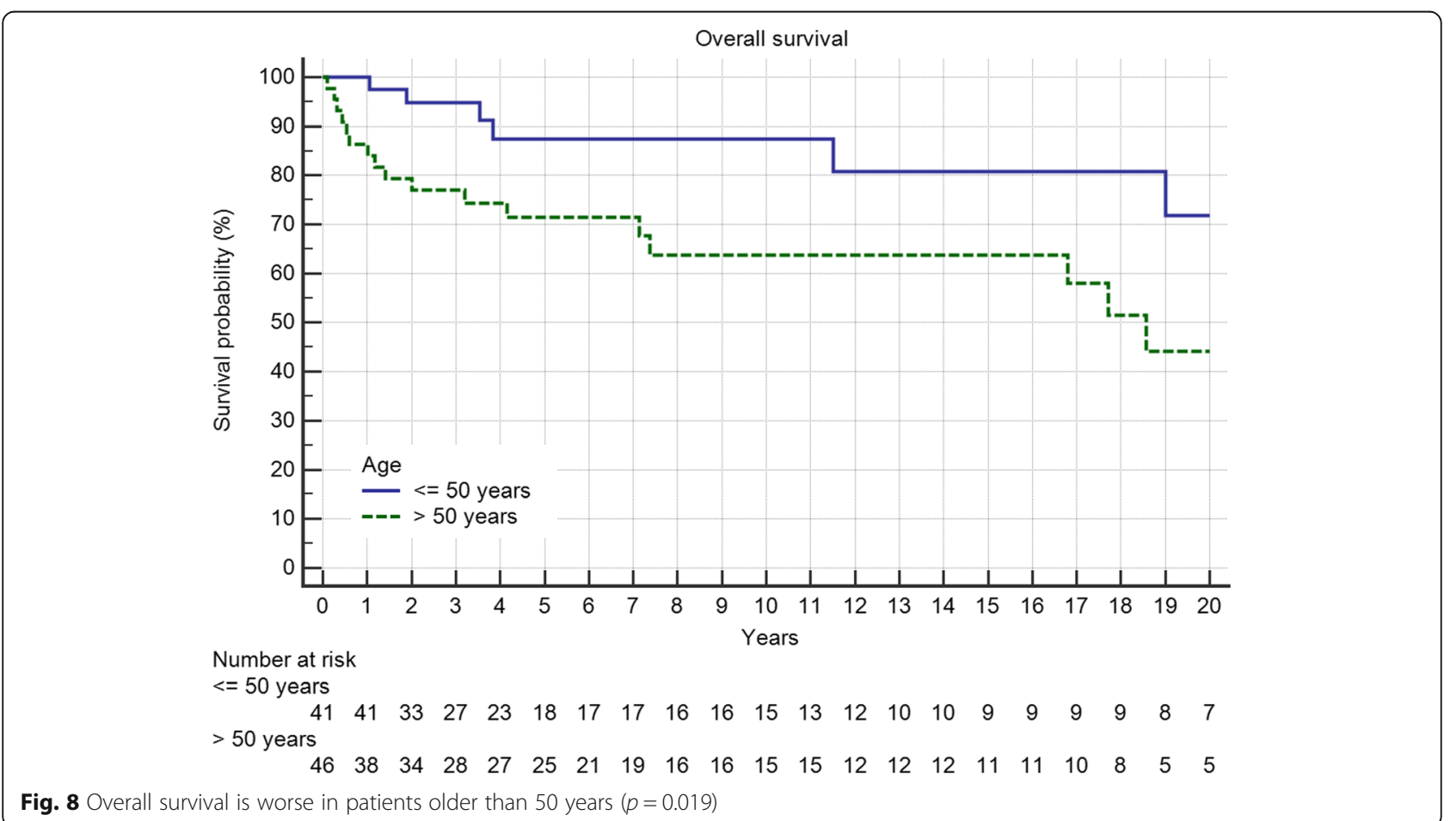


Table 2 Cox proportional-hazards regression for overall survival in relation to grading, metastatic disease, age, margin status, location and local recurrence

\begin{tabular}{|c|c|c|c|c|}
\hline \multirow[t]{2}{*}{ Variables } & \multicolumn{2}{|l|}{$\underline{\text { Univariate analysis }}$} & \multicolumn{2}{|l|}{$\underline{\text { Multivariate analysis }}$} \\
\hline & Hazard ratio $(95 \% \mathrm{Cl})$ & $p$-value & Hazard ratio $(95 \% \mathrm{Cl})$ & $p$-value \\
\hline Grading & $2532(1360-4715)$ & 0,0034 & $3208(1380-7457)$ & 0,0067 \\
\hline Metastatic disease & $11,477(4,6288-28,4589)$ & $<0,0001$ & $14,763(4819-45,229)$ & $<0,0001$ \\
\hline Age $<=50$ & $2906(1143-7389)$ & 0,0251 & $0,307(0,115-0,822)$ & 0,0188 \\
\hline Margin status & $1311(0,642-2678)$ & 0,4571 & $1152(0,4997-2655)$ & 0,7401 \\
\hline Pelvic/Non-pelvic & $0,309(0,165-0,578)$ & 0,0002 & $0,441(0,231-0,845)$ & 0,0136 \\
\hline Local recurrence & $2614(1115-6125)$ & 0,0270 & $1233(0,448-3394)$ & 0,6847 \\
\hline
\end{tabular}

$P$-values in bold indicates significance

tumor and the heterogenous distribution of therapy and localization in these studies [3, 30-32]. Bauer et al. treated 40 patients with enchondromas and 40 patients with low-grade CS. His results showed no difference between groups [33]. So intralesional curettage with and without adjuvants is a valid option in most of those patients, but as stated above, central lesions should be resected because of their higher recurrence rates [27].

Metastatic disease was seen in $23 \%$. This is about the same as described by other authors [10,34-36]. There are series with a lesser $[37,38]$ or a higher $[16,39]$ proportion of metastatic disease. This reflects the importance of patient selection. The inclusion of initially non-metastasized patients only, patients with G2/3 lesions only or patients with axial or pelvic localizations only has a strong impact on MD and survival. In general MD is bad news for the patient with a 5 -years overall survival of less than $50 \%$. As shown in Table 2 , MD is the most significant negative prognostic factor. There are patients, in whom metastatic disease is manageable by resection, local radiation or systemic therapy, leading to survival rates of $10-30 \%$ after 10 years, as also in this study. But this is the exception, mainly seen in G1 tumors $[9,34,40]$. Our results show, that MD is more common in G2/3 lesions as described by others [9, 34, $39,41]$ but it is independent from surgical margins with the same rate of $\mathrm{MD}$ in $\mathrm{R} 0$ and $\mathrm{R} 1$ resected patients, and also independent from LR. This is in some respect in contrast to the literature $[9,10,35]$ but other authors did see the same, confirming grade and location [42] as risk factors or grade as the only significant risk factor [16] for MD in multivariate analyses. In a large survey in Finland [36] the decade of diagnosis was the only significant factor on MD with an increased risk in the 1980s.

One of the most urgent questions is which margin should be obtained and how does margin influence LR and OS. In our study, local recurrence-free survival was significantly associated with margin status and LR influenced OS as in most of the published studies [9, 35, 43]. But in our data as well as in previous publications, LR and margin status showed no effect on overall survival in multivariate analysis [34]. We have to admit, that we only could include 2 cases with a R2 margin. Those seem to have a worse prognosis. There are not many studies including margin status in a multivariate analysis of overall survival $[7,10]$. Lee shows a significant impact of margins on overall survival for patients with high-grade CS but the curves for wide and marginal resections did separate only after 120 months with just two events in the marginal group later on [10]. Fiorenza in 2002 reported findings identical to ours, namely a significant influence of LR on OS in univariate analysis and no influence of margin status in multivariate analysis [9]. LR remained significant as did grade and location. So in concordance with other groups, we conclude that LR after adequate resection is more likely to be a marker of the aggressiveness of the tumor than a consequence of failed local therapy [34, 44, 45]. We still maintain the premise of adequate resection, but some authors state that also intracompartmental grade 2 chondrosarcomas with a non-aggressive radiologic pattern can be treated by curettage without negatively affecting prognosis [46]. In patients with local recurrence but without MD, further aggressive surgery appears to constitute a good chance of cure (64\% published by Fiorenza et al.) [9].

\section{Conclusions}

The mainstay of therapy in chondrosarcoma of bone is surgery. Risk factors such as tumor grading, metastatic disease, age and location significantly influence overall survival. Margin status did influence local recurrence-free survival but not overall survival. Regarding the latter, the literature is inconclusive mainly due to a large heterogeneity of the study populations. Chondrosarcomas of the pelvis have a higher risk of local recurrence and should therefore be treated more aggressively at least to avoid local complications.

\section{Abbreviations}

CS: Chondrosarcoma; CT: Computed Tomography; G1, G2, G3: Grading according to the French Federation of Cancer Centers grading system; LR: Local recurrence; LRFS: Local recurrence-free survival; MD: Metastatic 
disease; MRI: Magnetic resonance imaging; n.s.: Not significant; OS: Overall survival; RO, R1, R2: Resection margin; WHO: World Health Organization

\section{Funding}

This study was not supported by any grants or external funding.

\section{Availability of data and materials}

The datasets used and/or analyzed during the current study are available from the corresponding author upon reasonable request.

\section{Authors' contributions}

JF Student doing his thesis on chondrosarcomas. He contacted the patients and acquiered the data. AK. Surgeon on many of the cases. AB. Radiologist reviewing the radiologic investigations. TK. Pathologist reviewing the pathologic investigations. LL. Oncologist. Every patient was discussed in the interdisciplinary panel and the decision not to treat was based on this. CB. Surgeon. FR. Reviewing the radiotherapy and deciding which patient to treat or not to treat. VJ. Surgeon on many of the cases. HRD. Corresponding author. Developed the study concept, did the final data analysis and provided the major clinical input in writing and revising of the manuscript. Each author has contributed significantly to, and is willing to take public responsibility for this study: its design, data acquisition, and analysis and interpretation of data. All authors have been actively involved in the drafting and critical revision of the manuscript. All authors read and approved the final manuscript.

\section{Ethics approval and consent to participate}

This study was approved by the ethics committee of the Medical Faculty, University of Munich. Written consent was obtained from all surviving patients included in this study. For non-surviving patients data were irreversibly anonymized as recommended by the ethics committee.

\section{Consent for publication}

Not applicable.

\section{Competing interests}

All authors have no financial and personal relationships with other people or organizations that could inappropriately influence (bias) this work. This study was not supported by any grants or external funding. The authors declare that they have no competing interests.

\section{Publisher's Note}

Springer Nature remains neutral with regard to jurisdictional claims in published maps and institutional affiliations.

\section{Author details}

${ }^{1}$ Musculoskeletal Oncology, Department of Orthopedics, Physical Medicine and Rehabilitation, University Hospital, Ludwig-Maximilians-University, Campus Grosshadern, Marchioninistr. 15, D-81377 Munich, Germany. 2Department of Radiology, University Hospital, LMU Munich, Munich, Germany. ${ }^{3}$ Institute of Pathology, University Hospital, LMU Munich, Munich, Germany. ${ }^{4}$ Department of Internal Medicine III (Oncology), University Hospital, LMU Munich, Munich, Germany. ${ }^{5}$ Department of Radiotherapy and Radiation Oncology, University Hospital, LMU Munich, Munich, Germany. ${ }^{6}$ CCU Molecular Radiation Oncology, German Cancer Research Center (DKFZ), Heidelberg, Germany.

\section{Received: 16 January 2018 Accepted: 10 August 2018}

\section{Published online: 24 August 2018}

\section{References}

1. Rozeman LB, Cleton-Jansen AM, Hogendoorn PC. Pathology of primary malignant bone and cartilage tumours. Int Orthop. 2006;30(6):437-44.

2. Hogendoorn P, Bovee J, Nielsen GP. Chondrosarcoma (grades I-III) including primary and secondary variants and periosteal chondrosarcoma. In: Fletcher CDM, Bridge JA, Hogendoorn PCW, Mertens F, editors. WHO Classification of Tumours of Soft Tissue and Bone, vol. 4. Lyon: International Agency for Research on Cancer (IARC); 2013. p. 264-9.

3. Ferrer-Santacreu EM, Ortiz-Cruz EJ, Diaz-Almiron M, Pozo Kreilinger J. Enchondroma versus chondrosarcoma in long bones of appendicular skeleton: clinical and radiological criteria-a follow-up. J Oncol. 2016;2016: 8262079.

4. Gelderblom H, Hogendoorn PC, Dijkstra SD, van Rijswijk CS, Krol AD, Taminiau AH, Bovee JV. The clinical approach towards chondrosarcoma. Oncologist. 2008;13(3):320-9.

5. van Maldegem AM, Gelderblom H, Palmerini E, Dijkstra SD, Gambarotti M, Ruggieri P, Nout RA, van de Sande MA, Ferrari C, Ferrari S, et al. Outcome of advanced, unresectable conventional central chondrosarcoma. Cancer. 2014; 120(20):3159-64.

6. Outani H, Hamada K, Imura Y, Oshima K, Sotobori T, Demizu Y, Kakunaga S, Joyama S, Imai R, Okimoto T, et al. Comparison of clinical and functional outcome between surgical treatment and carbon ion radiotherapy for pelvic chondrosarcoma. Int J Clin Oncol. 2016:21(1):186-93.

7. Andreou D, Gilg MM, Gosheger G, Werner M, Hardes J, Pink D, Leithner A, Tunn PU, Streitburger A. Metastatic potential of grade I chondrosarcoma of bone: results of a multi-institutional study. Ann Surg Oncol. 2016;23(1):120-5.

8. Nota SP, Braun Y, Schwab JH, van Dijk CN, Bramer JA. The identification of prognostic factors and survival statistics of conventional central chondrosarcoma. Sarcoma. 2015;2015:623746.

9. Fiorenza F, Abudu A, Grimer RJ, Carter SR, Tillman RM, Ayoub K, Mangham DC, Davies AM. Risk factors for survival and local control in chondrosarcoma of bone. J Bone Joint Surg (Br). 2002;84(1):93-9.

10. Lee FY, Mankin HJ, Fondren G, Gebhardt MC, Springfield DS, Rosenberg AE, Jennings LC. Chondrosarcoma of bone: an assessment of outcome. J Bone Joint Surg Am. 1999;81(3):326-38.

11. Giuffrida AY, Burgueno JE, Koniaris LG, Gutierrez JC, Duncan R, Scully SP. Chondrosarcoma in the United States (1973 to 2003): an analysis of 2890 cases from the SEER database. J Bone Joint Surg Am. 2009;91(5):1063-72.

12. Mochizuki $\mathrm{K}$, Yamaguchi $\mathrm{H}$, Umeda $\mathrm{T}$. The management of pelvic chondrosarcoma in Japan. Japanese Musculo-Skeletal Oncology Group. Int Orthop. 2000;24(2):65-70

13. Pring ME, Weber KL, Unni KK, Sim FH. Chondrosarcoma of the pelvis. A review of sixty-four cases. J Bone Joint Surg Am. 2001;83-A(11):1630-42.

14. Donati D, El Ghoneimy A, Bertoni F, Di Bella C, Mercuri M. Surgica treatment and outcome of conventional pelvic chondrosarcoma. J Bone Joint Surg (Br). 2005:87(11):1527-30.

15. Weber $\mathrm{KL}$, Pring ME, Sim FH. Treatment and outcome of recurrent pelvic chondrosarcoma. Clin Orthop Relat Res. 2002;397:19-28.

16. Sheth DS, Yasko AW, Johnson ME, Ayala AG, Murray JA, Romsdahl MM Chondrosarcoma of the pelvis. Prognostic factors for 67 patients treated with definitive surgery. Cancer. 1996;78(4):745-50.

17. Ozaki T, Hillmann A, Lindner N, Blasius S, Winkelmann W. Chondrosarcoma of the pelvis. Clin Orthop Relat Res. 1997:337:226-39.

18. Mermerkaya MU, Bekmez S, Karaaslan F, Danisman M, Kosemehmetoglu K Gedikoglu G, Ayvaz M, Tokgozoglu AM. Intralesional curettage and cementation for low-grade chondrosarcoma of long bones: retrospective study and literature review. World J Surg Oncol. 2014;12:336.

19. Goud AL, Wuyts W, Bessems J, Bramer J, van der Woude HJ, Ham J. Intraosseous atypical chondroid tumor or chondrosarcoma grade 1 in patients with multiple osteochondromas. J Bone Joint Surg Am. 2015;97(1):24-31.

20. Campanacci DA, Scoccianti G, Franchi A, Roselli G, Beltrami G, Ippolito M, Caff G, Frenos F, Capanna R. Surgical treatment of central grade chondrosarcoma of the appendicular skeleton. J Orthop Traumatol. 2013: 14(2):101-7

21. Leerapun T, Hugate RR, Inwards CY, Scully SP, Sim FH. Surgical management of conventional grade I chondrosarcoma of long bones. Clin Orthop Relat Res. 2007:463:166-72.

22. Di Giorgio L, Touloupakis G, Vitullo F, Sodano L, Mastantuono M, Villani C. Intralesional curettage, with phenol and cement as adjuvants, for low-grade intramedullary chondrosarcoma of the long bones. Acta Orthop Belg. 2011; 77(5):666-9.

23. Hanna SA, Whittingham-Jones $P$, Sewell MD, Pollock RC, Skinner JA Saifuddin A, Flanagan A, Cannon SR, Briggs TW. Outcome of intralesional curettage for low-grade chondrosarcoma of long bones. Eur J Surg Oncol. 2009;35(12):1343-7.

24. Donati D, Colangeli S, Colangeli M, Di Bella C, Bertoni F. Surgical treatment of grade I central chondrosarcoma. Clin Orthop Relat Res. 2010;468(2):581-9.

25. Verdegaal SH, Brouwers HF, van Zwet EW, Hogendoorn PC, Taminiau AH. Low-grade chondrosarcoma of long bones treated with intralesional curettage followed by application of phenol, ethanol, and bone-grafting. J Bone Joint Surg Am. 2012;94(13):1201-7. 
26. Meftah M, Schult P, Henshaw RM. Long-term results of intralesional curettage and cryosurgery for treatment of low-grade chondrosarcoma. J Bone Joint Surg Am. 2013;95(15):1358-64.

27. Funovics PT, Panotopoulos J, Sabeti-Aschraf M, Abdolvahab F, Funovics JM, Lang S, Kotz Rl, Dominkus M. Low-grade chondrosarcoma of bone: experiences from the Vienna bone and soft tissue tumour registry. Int Orthop. 2011;35(7):1049-56

28. Schwab JH, Wenger D, Unni K, Sim FH. Does local recurrence impact survival in low-grade chondrosarcoma of the long bones? Clin Orthop Relat Res. 2007:462:175-80.

29. Streitburger A, Ahrens H, Balke M, Buerger H, Winkelmann W, Gosheger G, Hardes J. Grade I chondrosarcoma of bone: the Munster experience. J Cancer Res Clin Oncol. 2009:135(4):543-50.

30. Yoo HJ, Hong SH, Choi JY, Moon KC, Kim HS, Choi JA, Kang HS. Differentiating high-grade from low-grade chondrosarcoma with MR imaging. Eur Radiol. 2009;19(12):3008-14.

31. Douis $H$, Singh L, Saifuddin A. MRI differentiation of low-grade from high-grade appendicular chondrosarcoma. Eur Radiol. 2014;24(1):232-40.

32. Kendell SD, Collins MS, Adkins MC, Sundaram M, Unni KK. Radiographic differentiation of enchondroma from low-grade chondrosarcoma in the fibula. Skelet Radiol. 2004;33(8):458-66.

33. Bauer $\mathrm{HC}$, Brosjo O, Kreicbergs A, Lindholm J. Low risk of recurrence of enchondroma and low-grade chondrosarcoma in extremities. 80 patients followed for 2-25 years. Acta Orthop Scand. 1995;66(3):283-8.

34. Andreou D, Ruppin S, Fehlberg S, Pink D, Werner M, Tunn PU. Survival and prognostic factors in chondrosarcoma: results in 115 patients with longterm follow-up. Acta Orthop. 2011;82(6):749-55.

35. Rizzo M, Ghert MA, Harrelson JM, Scully SP. Chondrosarcoma of bone: analysis of 108 cases and evaluation for predictors of outcome. Clin Orthop Relat Res. 2001;391:224-33.

36. Soderstrom M, Ekfors TO, Bohling TO, Teppo LH, Vuorio El, Aro HT. No improvement in the overall survival of 194 patients with chondrosarcoma in Finland in 1971-1990. Acta Orthop Scand. 2003:74(3):344-50.

37. Bjornsson J, McLeod RA, Unni KK, Ilstrup DM, Pritchard DJ. Primary chondrosarcoma of long bones and limb girdles. Cancer. 1998;83(10):2105-19.

38. Angelini A, Guerra G, Mavrogenis AF, Pala E, Picci P, Ruggieri P. Clinical outcome of central conventional chondrosarcoma. J Surg Oncol. 2012; 106(8):929-37.

39. Ozaki T, Hillmann A, Linder N, Blasius S, Winkelmann W. Metastasis of chondrosarcoma. J Cancer Res Clin Oncol. 1996;122(10):629-32.

40. Muller PE, Durr HR, Nerlich A, Pellengahr C, Maier M, Jansson V. Malignant transformation of a benign enchondroma of the hand to secondary chondrosarcoma with isolated pulmonary metastasis. Acta Chir Belg. 2004; 104(3):341-4.

41. Hayashi T, Tsuda N, Iseki M, Kishikawa M, Shinozaki T, Hasumoto M. Primary chondrosarcoma of the lung. A clinicopathologic study. Cancer. 1993;72(1):69-74.

42. Bindiganavile S, Han I, Yun JY, Kim HS. Long-term outcome of chondrosarcoma: a single institutional experience. Cancer Res Treat. 2015; 47(4):897-903.

43. Gitelis S, Bertoni F, Picci P, Campanacci M. Chondrosarcoma of bone. The experience at the Istituto Ortopedico Rizzoli. J Bone Joint Surg Am. 1981; 63(8):1248-57.

44. Gronchi A, Miceli R, Fiore M, Collini P, Lozza L, Grosso F, Mariani L, Casali PG. Extremity soft tissue sarcoma: adding to the prognostic meaning of local failure. Ann Surg Oncol. 2007;14(5):1583-90.

45. Brennan MF. The enigma of local recurrence. The Society of Surgical Oncology. Ann Surg Oncol. 1997;4(1):1-12.

46. Cho WH, Song WS, Jeon DG, Kong CB, Koh JS, Kim JI, Lee SY Oncologic impact of the curettage of grade 2 central chondrosarcoma of the extremity. Ann Surg Oncol. 2011:18(13):3755-61.

\section{Ready to submit your research? Choose BMC and benefit from:}

- fast, convenient online submission

- thorough peer review by experienced researchers in your field

- rapid publication on acceptance

- support for research data, including large and complex data types

- gold Open Access which fosters wider collaboration and increased citations

- maximum visibility for your research: over $100 \mathrm{M}$ website views per year

At BMC, research is always in progress.

Learn more biomedcentral.com/submissions 